\title{
Síntesis de la discusión de las ponencias sobre Psicología y Didáctica de las ciencias de la naturaleza
}

\author{
MonTSERRAT BENLLOCH
}

Universidad de Barcelona

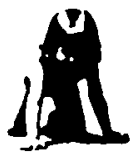

En la discusión posterior a las ponencias se reconoció un área de investigación común, en el dominio específico de las ciencias, tanto para la didáctica como para la psicología, pero se señalaron las ventajas de potenciar una variedad de ellas de acuerdo a los problemas, finalidades y métodos que las reúnen (Pozo). En este sentido se plantearon algunos núcleos de discusión en torno a la oportunidad de las investigaciones realizadas hasta el momento, su aplicabilidad y las limitaciones de sus resultados.

A) Uno de esos núcleos se configuró a partir de los desajustes entre la práctica educativa y la investigación.

Algunas críticas se centraron en los riesgos de traspasar a la práctica, de forma automática y acrítica, resultados e interpretaciones de la investigación. Un ejemplo de esto en clave grotesca plantearía usar las ideas previas en el aula con la intención de someterlas rápidamente a un conflicto cognitivo para alcanzar de inmediato un cambio conceptual (Pozo, Gil).

Se señaló que la primera parte de la frase de Ausubel estaba bastante conseguida (Luque, Pozo), a juzgar por el catálogo ingente de ideas de los alumnos, que veníamos recavando desde los últimos años, pero que lamentablemente este catálogo no garantizaba una mejora en las intervenciones desde la práctica (García).

La perspectiva histórica siempre ayuda y ella contribuyó a enfriar estas preocupaciones. En este sentido, la discusión remitió a los efectos prácticos de los diferentes proyectos que para unos han entorpecido los avances y mejoras de los procesos de enseñanza y aprendizaje (Gil se refirió a los proyectos de Ciencia Integrada y Enseñanza por Descubrimiento), y para otros han supuesto una buena muestra del dinamismo y construcción progresiva de la didáctica de las ciencias como disciplina ( $R$. Hernández y A. Candela). 
En la discusión quedó claro que si bien la práctica en el aula puede alimentarse saludablemente de la información procedente de las investigaciones (en ocasiones, incluso a riesgo de cierta indigestión) éstas no alcanzan siempre a poder responder con la premura requerida. Desde la investigación obviamente no se pueden ofrecer respuestas automáticas por muy conscientes que sean los investigadores de las necesidades y exigencias de los docentes. En esta línea se hizo (Llorens) una demanda enormemente sensata, a la vez que se afirmó un reconocimiento optimista de los beneficios irreversibles que la investigación genera en la práctica. Se propuso que, mientras las líneas de investigación abiertas seguían tratando de establecer más claridad conceptual sobre los temas que preocupan, se buscara alguna teoría provisional..., modesta..., que permitiera a los profesores tomar decisiones urgentes, y que se investigara sobre ella. Con esta intervención se sugería que los investigadores deberían permitirse la licencia de elaborar soluciones más coyunturales, menos definitivas y más simples, pero más eficaces para mejorar el trabajo en el aula.

B) Un segundo núcleo trató sobre la estructura de los contenidos del área y su idoneidad para el aprendizaje, así como su uso (muy discutido) como unidad de análisis en la investigación. En este núcleo se plantearon dos tipos de inquietudes que fueron solapándose de modo sucesivo.

Desde la perspectiva de la investigación, se defendió la necesidad de encontrar una unidad de análisis que fuera relevante en la práctica educativa (Coll). Por otra parte, se revisó la idoneidad de una unidad de análisis sacada de una estructura de la disciplina demasiado académica. De modo que buena parte de la discusión remitió tanto a la investigación en sus aspectos más técnicos como a la educación científica.

Se apuntó (Candela) el riesgo de que la enseñanza, después de todos estos años de investigación, trate de conseguir que las «ideas de los alumnos» pasen a convertirse en concepciones que mantiene en este momento la ciencia. Esta presunción podría traducirse en aplicaciones de un método inductivo que proceda desde el conocimiento cotidiano al conocimiento de la ciencia. Se propuso que, en lugar de plantear contenidos científicos acabados o cerrados, la enseñanza de la ciencia se concibiera como un proceso de aproximación sucesivo, de modo que la didáctica no planteara restricciones en razón a la edad de los alumnos. Otras personas (R. Hernández) reclamaron una intervención específica para los más pequeños apelando a la falta de formación científica de los maestros en párvulos.

Por último, y para justificar la oportunidad de una investigación «naturalista» (que comentaremos más adelante), se hizo (M. Rodrigo) un resumen-análisis de las diferentes formas de articular o relacionar el conocimiento no científico y el científico: se admitió que una de estas formas consiste en incluir contenidos científicos relevantes para la disciplina y no relevantes para el aula. Otra posibilidad es usar contenidos científicos que tengan relevancia con problemas cotidianos. Aunque se advierte que esto puede ser peligroso, porque lo que se plantea en lo cotidiano no necesariamente permite construir lo que se ha denominado «el mesocosmos». Y por último, si se decide no sustituir unas ideas previas por otras científicas, sino que se reconoce que ambas se pueden superponer y activar en función de usos distintos, se podría sugerir un criterio en función de las edades. Seguir un principio de correspondencia máxima entre la relevancia cotidiana y la científica entre los más pequeños, pero a medida que se sube 
en edad plantear un conjunto de contenidos que no necesariamente se corresponde con contenidos de la vida cotidiana.

Alguien mencionó la conveniencia de desacralizar los contenidos y darles una estructura que no sea exactamente la de la ciencia. En este sentido se subrayó (Carretero) un cierto desajuste entre los resultados de las investigaciones relativas a las ideas de los alumnos y la estructura de los contenidos que se imparten en secundaria. Por una parte se propone unos contenidos que siguen siendo resúmenes de los manuales de las carreras de ciencias... Y por otra se focaliza, en muchas ocasiones, sobre las ideas previas o erróneas para reflejar, de modo implícito, que ellas son el resultado de las dificultades del aprendizaje del propio alumno, o si se prefiere del fracaso de la enseñanza. Va de suyo que, mientras se emplee como estrategia aflorar las ideas incorrectas del alumno para manifestar el fracaso del aprendizaje, y los contenidos sigan estructurados de acuerdo a la lógica de las disciplinas universitarias, se cae en una contradicción difícil de superar. Se sugiere (Carretero) cambiar el foco de atención y pasar a considerar aspectos más positivos del aprendizaje de los alumnos. Se plantea algo que, en homenaje a la frase más mencionada en esta discusión, podríamos expresar como sigue: «averígüese lo que si aprenden bien los alumnos... y hágase una secuenciación del currículum en consecuencia».

C) Un tercer núcleo de discusión centró el debate sobre la investigación.

Este fue especialmente fecundo y muy chispeante, a pesar de que todos los participantes se reconocen en las filas del «constructivismo».

Se discutió sobre «qué» y «cómo» hay que investigar, planteándose una polémica en torno al objeto, los métodos de investigación y la pertinencia de fragmentar las investigaciones en uno u otro tipo de unidades de análisis. Se reconoció que los métodos estaban muy marcados por la finalidad y uso que se decide dar a los objetos de las investigaciones (Coll).

Se dejó claro que la investigación en este dominio debe pasar a una fase que complemente los conocimientos descriptivos que poseemos con otros más explicativos (Pozo).

Se llegó a un acuerdo, por lo menos terminológico, sobre la importancia de orientar las nuevas investigaciones sobre las ideas de los alumnos en la dirección del contexto en que se adquieren, activan o se usan. Este acuerdo se desdobló rápidamente. Se diferenciaron posturas, en relación con las intenciones y objetivos que persiguen los diferentes investigadores, y que en buena parte justifican las estrategias para estudiar la naturaleza contextual de las ideas de los alumnos.

En el caso de las investigaciones que toman por objeto los procesos de enseñanza y aprendizaje, se considera (Coll) imprescindible tomar en cuenta el marco donde los conocimientos se construyen y se usan. En este caso, interesa conocer el contenido, pero dentro de la significación que ese contenido pueda tener en el aula donde se aprende y se emplea.

Desde otra posición se reconoce (Pozo) que las investigaciones sobre las ideas previas o de naturaleza no formal más descontextualizadas del medio escolar han corrido a cargo de los psicólogos, a los que en general les trae sin cuidado los problemas didácticos. Y ello se nota, por ejemplo, tanto en la falta de ubicación de la investigación que se realiza en la secuencia de la materia como en el empleo de un solo tipo de tarea, etcétera.

Se reconoce que las investigaciones didácticas efectivamente sí han sido más 
contextualizadas..., pero todo el mundo admite que sus resultados son más descriptivos que explicativos. Todo esto lleva a pensar que sería muy necesario realizar investigaciones que traten de compatibilizar ese conocimiento científico que se está trabajando en el aula y el conocimiento no científico que tiene el alumno y que está siendo activado. Esta perspectiva sitúa el problema fuera de un contexto meramente didáctico y obliga a un control de otras variables no solamente escolares (Pozo).

En relación a la diversidad de intereses y perspectivas que permite este campo de investigación común a psicólogos y didactas pero diferenciado en cuanto a sus intereses, objetivos y métodos, otra contribución se suma a las dos anteriores.

Se planteó (M. J. Rodrigo) la necesidad de conocer mejor cómo operan los diferentes planos de activación de las ideas científicas y las no científicas en los niños.

$\mathrm{Si}$ aceptamos que no se trata de sustituir unas ideas informales por otras ideas científicas, sino que ambos tipos de ideas coexisten y que se activan diferencialmente en función de contextos de uso distinto (como señala Pozo), tal vez sería interesante realizar una «investigación naturalista» para conocer cuáles serían los contextos que disparan en un caso epistemologías cotidianas y, en otro, conocimientos de tipo científico.

Se plantea que no necesariamente la barrera de un tipo de activación y de otra tiene que ver con lo que se ha llamado «contextos de aprendizaje espontáneo» y «contextos formalizados». Se señaló que no está nada claro que la escuela sea el lugar donde el conocimiento científico trabaje, se use y active, mientras que el medio extraescolar se limite a los conocimientos informales.

Una investigación que estudie cómo son esas situaciones permitiría despreocuparse por sustituir un tipo de conocimientos por otro y aclararía en qué casos se activan unos y en cuáles se activan otros. 